\title{
Von Willebrand Factor Activity Actual to Control Ratio Measurement
}

National Cancer Institute

\section{Source}

National Cancer Institute. von Willebrand Factor Activity Actual to Control Ratio

Measurement. NCI Thesaurus. Code C147447.

The determination of the ratio of the biological activity of von Willebrand factor dependent coagulation in a subject's specimen when compared to the same activity in a control specimen. The measurement may be expressed as a ratio or percentage. 